\title{
The comparative study of the effect of telmisartan and ramipril on diabetic profile in hypertensive pre-diabetic patients
}

\author{
Abdullah Ansari ${ }^{1}$, Ayesha Raoof ${ }^{2 *}$ \\ ${ }^{1}$ Department of Pharmacology, Ayaan Institute of Medical Sciences, Moinabad, Telangana, India \\ ${ }^{2}$ Department of Medicine, HAL Medical Centre, Hyderabad, Telangana, India
}

Received: 13 June 2020

Revised: 14 July 2020

Accepted: 15 July 2020

*Correspondence:

Dr. Ayesha Raoof,

Email: aa66137@gmail.com

Copyright: (C) the author(s), publisher and licensee Medip Academy. This is an open-access article distributed under the terms of the Creative Commons Attribution Non-Commercial License, which permits unrestricted non-commercial use, distribution, and reproduction in any medium, provided the original work is properly cited.

\begin{abstract}
Background: Hypertension, a common cardiovascular disease, is being increasingly associated with other co-morbid conditions like Diabetes mellitus, worsening its outcome. Both telmisartan and ramipril are effective anti hypertensive agents. The present study compares the efficacy of telmisartan and ramipril in controlling or preventing the progression of pre-diabetes to diabetes in stage 1 hypertensive patients.

Methods: A prospective, randomised, single centre, comparative observational study is conducted over a period of 12 months on stage 1 hypertensive patients with pre-diabetes. 60 patients are recruited and randomised into two treatment groups. They received the assigned drug for a period of 12 months and are followed up. At each visit, blood pressure was measured and diabetic profile was tested.

Results: This study showed that both telmisartan and ramipril controlled the blood pressure effectively. Telmisartan controlled the progression of fasting blood sugar and glycosylated haemoglobin better than ramipril in stage 1 hypertensive patients with pre diabetes.

Conclusions: Both telmisartan and ramipril were affecting in controlling the blood pressures. Telmisartan has a statistically significant effect in preventing the progression of prediabetes to diabetes mellitus in stage 1 hypertensive patients with pre diabetes when compared with ramipril.
\end{abstract}

Keywords: Telmisartan, Ramipril, Hypertension, Pre-diabetes, Fasting blood sugar, Glycosylated haemoglobin

\section{INTRODUCTION}

Hypertension, commonly known as high blood pressure, is a condition in which the blood flows through the blood vessels with a force greater than the normal. The seventh report of the Joint National Committee on the prevention, detection, evaluation and treatment of high blood pressure (JNC 7) defines hypertension as SBP $140 \mathrm{mmHg}$ and greater and/or DBP $90 \mathrm{mmHg}$ or greater. ${ }^{1}$ Individuals with systolic blood pressure (SBP) $140-159 \mathrm{mmHg}$ and/or diastolic blood pressure (DBP) $90-99 \mathrm{mmHg}$ are classified as stage 1 hypertension while those at or above SBP $160 \mathrm{mmHg}$ and/or DBP $100 \mathrm{mgHg}$ constitute stage
2 hypertension. The prevalence of hypertension is increasing rapidly in developing countries, where poor hypertension treatment and control contribute to the growing epidemic of cardiovascular disease. ${ }^{2}$ High blood pressure currently causes two thirds of all strokes and half of all cases of ischemic heart disease worldwide. ${ }^{3}$ Thus high blood pressure remain the leading cause of death worldwide and one of the world's great public health problems.

Amongst the existing co-morbid conditions, hypertension has the most likely association with diabetes mellitus (DM) and it co-exists at a greater frequency than chance 
alone would predict. $^{4}$ Development of DM in hypertensive patients accelerates the rate of progression of atherosclerosis which in turn worsens the hypertension and its outcomes like cardiac diseases, peripheral vascular diseases, stroke retinopathy and nephropathy., ${ }^{4,5}$ Therefore managing hypertensive patients with prediabetes by rational use of anti-hypertensive medications is a growing important need for preventing and/or delaying the development of DM and its related complications.

Pre-diabetic state as per American Diabetes Association (ADA) guidelines is a phase of impaired glucose tolerance $2 \mathrm{hr}$ PG in $75 \mathrm{~g}$ oral glucose tolerance test 140$199 \mathrm{mg} / \mathrm{dl}$ and/or impaired fasting glucose $100-125 \mathrm{mg} / \mathrm{dl}$ and/or Hbalc 5.7-6.4\%. ${ }^{6}$ The patho-physiology of prediabetes is similar to type II DM, two basic defects are insulin resistance and early beta cell failure. In prediabetes, the rapid oscillations of insulin secretion are lost and amplitude of large pulses is decreased. The glycaemic excursions after each meal responses to meals tends to be lower than normal, both the second phase of insulin secretion is delayed and prolonged. ${ }^{7}$

As the hypertensive patients have the higher risk of progression of pre-diabetes to diabetes, the rational use of such anti- hypertensive drug which could control / delay the progression of this process is the emerging challenge for the today's world health care.

Telmisartan is an anti hypertensive drug, belonging to the class of angiotensin II receptor blocker (ARB). It binds to the AT I receptor with high affinity. ARBs potently and selectively inhibit both most of the biological effects of angiotensin II, including angiotensin II induced contraction of vascular smooth muscle, rapid pressure responses, slow pressure responses, thirst, vasopressin release, aldosterone secretion, release of adrenal cathecolamines, enhancement of noradrenergic neuro transmission, increase in sympathetic tone, changes in renal function and cellular hypertrophy and hyperplasia. ${ }^{8}$

Ramipril is an anti hypertensive drug, belonging to the class of angiotensin converting enzyme inhibitors (ACE inhibitors). The essential effect is to inhibit the conversion of inactive angiotensin I to angiotensin II. ACE inhibitors are highly selective drugs as they do not interact directly with other components of the RAS and clinical effects are mainly due to suppression of synthesis of angiotensin II. As ACE inhibitors increase bradykinin levels that stimulates prostaglandin biosynthesis, that also contributes to the pharmacological effects. It lowers the systemic vascular resistance and mean, diastolic, systolic blood pressures in various hypertensive states. ${ }^{9}$

ARBs differ from ACE inhibitors in several important aspects i.e. ARBs reduce activation of AT I receptor more effectively than do ACE inhibitors; In contrast to ACE inhibitors ARBs permit activation of AT II receptors; ACE inhibitors may increase angiotensin (1-7) levels more than do ARBs; ACE inhibitors increase the levels of a number of ACE substrates, including bradykinin and Ac-SDKP. ${ }^{10}$

The objective of the present study is to compare the efficacy of telmisartan and ramipril in controlling or preventing the progression of pre-diabetes to diabetes in stage 1 hypertensive patients.

\section{METHODS}

This is an open labelled, single centre prospective randomised study conducted on 60 hypertensive prediabetic patients attending general medicine outpatient department of Ayaan Institute of Medical sciences.

Study population includes patients attending general medicine outpatient department of Ayaan Institute of Medical Sciences satisfying the eligibility criteria.

Study was conducted at Ayaan Institute of Medical Sciences (Department of Pharmacology in collaboration with Department of General Medicine Ayaan Institute of Medical Sciences)

Duration of study was of 12 months after first visit for each subject. Study period was from October 2018 to February 2020.

Sample size involves group A-Telmisartan -30 patients. Group B - Ramipril-30 patients (total 60 patients).

\section{Inclusion criteria}

Denovo or recently detected stage I hypertensive patients as per JNC 8 guidelines and pre-diabetic patients as per ADA 2017 guidelines, either gender, age between 31 to 60 years, who are willing to give informed consent and those willing to come for follow up, as advised were included.

\section{Exclusion criteria}

Known diabetic patients, patients with renal insufficiency, secondary hypertension, coronary artery disease, pregnant and lactating women, patients with bronchial asthama, patients with previous history of coronary vascular event, polycystic ovarian disease, renal artery stenosis, known hypersensitivity to ACE and ARB, renal and hepatic disease, major illness, use of any other experimental drug, major psychiatric disorder, unknown substance abuse and patients not giving consent.

The study is conducted after obtaining the approval from institutional ethics committee. After screening 85 patients, 60 patients satisfying the inclusion and exclusion criteria are enrolled in the study. The enrolled patients are randomised by simple randomization (odd/even number method) into group A or group B. 
After taking informed consent, the data was recorded in a case record form. The data collected includes demographic data like patients name, age, gender, address, history and duration of hypertension, h/o associated comorbidities and risk factors. History was taken to rule out other causes of hypertension.

All the patients recruited in the study underwent a detailed physical examination including assessment for other complications of hypertension. At the baseline and at each visit blood pressure was measured with appropriately sized cuff in the right upper arm with patient seated and after 15 minutes of rest. Three recordings were taken at 15 min apart and their mean reading were taken as clinical blood pressure.

Glucose metabolism was evaluated by fasting blood glucose (FBG) and glycosylated haemoglobin (HbA1C). Blood samples for laboratory analysis were obtained at approximately 9:00 am following overnight fasting before and at the end of 12 months study period. FBG was measured with the glucose oxidase method and HbA1C with high resolution chromatography. ${ }^{11,12}$

Data was spread in Microsoft Excel Sheet and analysed using Excel (2010 version) statistical tool. Data is presented as frequency and percentages of patients with characteristics for categorical variable and as mean \pm standard deviation for continuous variables.

A paired analysis of the different parameters was performed, comparing the parameters determined with Telmisartan therapy with those determined with Ramipril therapy. Differences between parameters obtained with telmisartan and ramipril therapy were analyzed. Students paired $\mathrm{T}$ test were used to compare values before and after 12 months of giving telmisartan and ramipril and the relative changes in values in response to the single drug within a group. Unpaired $\mathrm{T}$ test was used for inter group comparison between telmisartan and ramipril. A p value of less than 0.05 was considered statistically significant.

\section{RESULTS}

All the 60 patients are between age group 31-60 years of age. $37(61.67 \%)$ of the patients are male and the remaining $23(38.33 \%)$ are females. All patients belonged to stage 1 hypertension according to JNC 7 criteria and were pre diabetics as per ADA guidelines. $50 \%$ of the patients comprising of $19(31.67 \%)$ males and 11 (18.33\%) females received telmisartan (group A). All patients tolerated telmisartan without any side effects during treatment with $40 \mathrm{mg}$ of telmisartan and blood pressure was effectively controlled. Remaining $50 \%$ of the patients comprising $18(30 \%)$ males and $12(20 \%)$ females received ramipril (group B). All the patients tolerated ramipril without any side effects during treatment with $5 \mathrm{mg}$ of ramipril and the blood pressure was effectively controlled.

\section{Fasting blood glucose}

The mean fasting blood glucose (FBG) of group A before the start of treatment was $115.36 \pm 6.5 \mathrm{mg} / \mathrm{dl}$ and after 12 months of treatment with Telmisartan was 106.6 \pm 11.2 (Table 3). FBG values increased in $16.67 \%$ of patients in Group A over a period of 12 months whereas FBG values decreased in $33.3 \%$ of the patients in group A (Table 1). The FBG values before and after treatment were compared which showed a p value of 0.01 (Table 4) indicating that the effect of Telmisartan on FBG was statistically significant. The mean FBG of group B before the start of treatment was $111.0 \pm 7.9$ and after 12 months of treatment with Ramipril was 112.6 \pm 12.8 (Table 3). FBG values increased in $30 \%$ of the patients in Group B and decreased in $20 \%$ of the patients in group B over a period of 12 months (Table 1). The FBG values before and after treatment with ramipril was compared which showed a $p$ value of 0.57 indicating that the effect of ramipril on FBG was not statistically significant. A comparison between the group A and group B was done which showed a $\mathrm{p}$ value of 0.039 indicating that the effect of telmisartan on FBG levels were statistically significant when compared to ramipril.

Table 1: Changes in FBG levels of the subjects after 12 months of treatment with telmisartan (group A) and ramipril (group B).

\begin{tabular}{|lll|}
\hline Groups & $\begin{array}{l}\text { Increase in } \\
\text { FBG }\end{array}$ & $\begin{array}{l}\text { Decrease in } \\
\text { FBG }\end{array}$ \\
\hline N (\%) & N (\%) \\
\hline Males (group A) & $6(10)$ & $13(21.67)$ \\
\hline Females (group A) & $4(6.67)$ & $7(11.67)$ \\
\hline Total (group A) & $10(16.67)$ & $20(33.33)$ \\
\hline Males (group B) & $11(18.33)$ & $7(11.67)$ \\
\hline Females (group B) & $7(11.67)$ & $5(8.34)$ \\
\hline Total (group B) & $18(30)$ & $12(20)$ \\
\hline
\end{tabular}

\section{Glycosylated haemoglobin}

The mean glycosylated haemoglobin (HbA1C) of group A before the start of treatment was $5.84 \pm 0.19$ and after 12 months of treatment with telmisartan was $5.72 \pm 0.35$ (Table 3). HbA1C values increased in $15 \%$ of patients in group A over a period of 12 months whereas HbA1C values decreased in $35 \%$ of the patients in group A (Table 1). The $\mathrm{HbA} 1 \mathrm{C}$ values before and after treatment were compared which showed a p value of 0.05 (Table 4) indicating that the effect of Telmisartan on HbA1C was statistically significant. The mean $\mathrm{HbA} 1 \mathrm{C}$ of group $\mathrm{B}$ before the start of treatment was $5.89 \pm 0.23$ and after 12 months of treatment with Ramipril was 5.96 \pm 0.38 (Table 3 ). HbA1C values increased in $28.3 \%$ of the patients in group B and decreased in $21.67 \%$ of the patients in group $\mathrm{B}$ over a period of 12 months (Table 2). The HbA1C values before and after treatment with ramipril was compared which showed a $\mathrm{p}$ value of 0.258 indicating that the effect of ramipril on HBA1C was not statistically significant. A comparison between the group A and group 
B was done which showed a p value of 0.027 (Table 4) indicating that the effect of telmisartan on FBG levels were statistically significant when compared to ramipril.

Table 2: Changes in HbA1C levels of the subjects after 12 months of treatment with telmisartan (group A) and ramipril (group B).

\begin{tabular}{|lll|}
\hline Groups & $\begin{array}{l}\text { Increase in } \\
\text { HbA1C }\end{array}$ & $\begin{array}{l}\text { Decrease in } \\
\text { HbA1c }\end{array}$ \\
\hline N (\%) & N (\%) \\
\hline Males (group A) & $6(10)$ & $13(21.67)$ \\
\hline Females (group A) & $3(5)$ & $8(13.33)$ \\
\hline Total (group A) & $9(15)$ & $21(35)$ \\
\hline Males (group B) & $9(15)$ & $9(15)$ \\
\hline Females (group B) & $8(13.33)$ & $4(6.67)$ \\
\hline Total (group B) & $17(28.33)$ & $13(21.67)$ \\
\hline
\end{tabular}

Table 3: Comparison of the mean of group $A$ (telmisartan) and group B (ramipril) on FBG and HbA1C levels before and after treatment.

\begin{tabular}{|c|c|c|}
\hline \multirow[t]{2}{*}{ Parameters } & $\begin{array}{l}\text { Group A } \\
\text { (telmisartan) }\end{array}$ & $\begin{array}{l}\text { Group B } \\
\text { (ramipril) }\end{array}$ \\
\hline & Mean+SD & Mean \pm SD \\
\hline \multicolumn{3}{|l|}{ FBG } \\
\hline 0 months & $115.3 \pm 6.5$ & $111 \pm 7.9$ \\
\hline 12 months & $106 \pm 11.2$ & $112.6 \pm 11.2$ \\
\hline \multicolumn{3}{|l|}{ HbA1C } \\
\hline 0 months & $5.84 \pm 0.19$ & $5.89 \pm 0.23$ \\
\hline 12 months & $5.72 \pm 0.35$ & $5.96 \pm 0.38$ \\
\hline
\end{tabular}

Table 4: Comparison of the $p$ value of group $A$ and group B on FBS and HbA1C before and after treatment and comparison between the group $A$ and group $\mathbf{B}$.

\begin{tabular}{|llll|} 
Parameters & $\begin{array}{l}\text { Group A } \\
\text { (telmisartan) }\end{array}$ & $\begin{array}{l}\text { Group B } \\
\text { (ramipril) }\end{array}$ & $\begin{array}{l}\text { Group } \\
\text { A vs } \\
\text { group B }\end{array}$ \\
\hline FBG & $0.01^{*}$ & 0.57 & $0.039^{*}$ \\
\hline HbA1C & $0.05^{*}$ & 0.258 & $0.027^{*}$ \\
\hline
\end{tabular}

$*$ p value $<0.05$ implies statistically significant.

\section{DISCUSSION}

The metabolic syndrome is described as the presence of visceral obesity, insulin resistance, (or) glucose intolerance, atherogenic dyslipidemia, hyperurecimia and hypertension in a patient. All entities are common cardiovascular risk factors with a calculated risk increase of 2-4 fold for cardiovascular diseases and death. ${ }^{13}$ Hypertension occurs twice as frequently in patients with diabetes compared with non-diabetic controls. ${ }^{13}$ Conversely, recent data suggest that hypertensive patients are more likely to develop diabetes than normotensive patient. ${ }^{13}$ Up to $75 \%$ of cardiovascular diseases in diabetic patient can be attributed to hypertension. ${ }^{13}$ Therefore primary goal of treating metabolic syndrome are prevention of diabetes mellitus type II and cardiovascular diseases.

Angiotensin II, a potent vasoconstrictor is a major determinant of blood pressure and is implicated in the pathogenesis of hypertension. Drugs that modify the renin - angiotensin- aldesterone system (RAAS) such as the ACE inhibitors and ARBs are widely accepted agents for the management of hypertension.

Although both of these drugs classes ultimately effect the action of angiotensin II, the differences in their mechanism of action have implications for their effects on other pathways and receptors that may have therapeutic implications. ${ }^{14,15}$

Both telmisartan and ramipril controlled blood pressures adequately, which is similar to the study conducted unser T, which showed that both ACE inhibitors \& ARBS are effective anti hypertensive agents that have been shown to reduced the risk of cardiovascular and renal events. ${ }^{14}$

The present study finding concludes that there is significant reduction in fasting blood glucose levels and $\mathrm{HbA1C}$ levels in the subjects receiving telmisartan. This is similar to the value and life randomised controlled trials that showed that ARB therapy substantially lowers the risk for diabetes type 2 compared to other antihypertensive therapies and placebo. The findings are also similar to a 12 months randomised double blind study, conducted by Derosa et al that showed an improvement in glucose metabolism and lipid metabolism in patients receiving telmisartan. ${ }^{16}$ Benson et al observed reduction in glucose, insulin and triglyceride level in telmisartan administered mice fed a diet rich in fat and carbohydratre. $^{17}$

Telmisartan partial agonist of ppar $\gamma$ \{peroxisome proliferator-activated receptor gamma $\}$ is unique in having chemical structure similar to insulin sensitizer i.e. pioglitazones. Ppar $\gamma$, a member of nuclear hormones receptor -super family, functions on a transcription factor that regulates the expressions of multiple gene involved in carbohydrate and lipid metabolism and inflammation. ${ }^{18}$ Hence ligands for ppar $\gamma$ like telmisartan which act as a partial agonist at therapeutic doses can decrease the risk for atherosclerosis by improving insulin sensitivity, reducing triglyceride level and decreasing visceral fat mainly in patients with type 2 diabetes and metabolic syndrome. Thus, it can be used not only in the treatment of hypertension but also for metabolic syndrome.

Telmisartan also reduces glucose and triglyceride levels and increase glucose uptake and GLUT-4 expressions factors that may translate into a favourable metabolic profile and potential insulin sensitizing activity of the drug. Telmisartan was shown to induce adiponectin via ppar $\gamma$ activation. ${ }^{19}$ Adiponectin is an adipose derived factor that augments and mimics metabolic and vascular actions of insulin. ${ }^{20}$ Thus it is possible that increased level 
of adiponectin contribute to improvement in insulin sensitivity. ${ }^{21}$ In addition telmisartan may have direct effect to augment insulin stimulated uptake. Telmisartan also induce ppar $\gamma$ in AT2 receptor deficient models, thus support concept that telmisartan could stimulate ppar $\gamma$ activity independent of AT 2 receptor blocking activity. ${ }^{17}$

The present study showed that there was no significant reduction in the fasting blood glucose and HbA1C levels in patients receiving ramipril which is in contrast to the DREAM trial 2005 - diabetes reduction assessment with ramipril \& rosiglitazone medication which was 3 years parallel group double blind trial on 2623 study/ 2646 control group. ${ }^{22}$ The study revealed modest benefit on regression to normoglycaemia, increased glycaemic control, lower incidence of development of T2 DM in patients with impaired FBG /impaired GTC. It showed development of diabetes in $17.12 \%$ of the patients treated with ramipril as compared to $18.48 \%$ control group. About $42.55 \%$ of the treated patients were normoglycaemic by the end of the study as compared to $38.25 \%$ in control group $(\mathrm{p}=0.001)$.

A major limitation of our study is the lack of a placebo controlled treatment arm. Another limitation is the small population size, which may obscure some of the effects between the drugs.

\section{CONCLUSION}

It may be concluded that both telmisartan and ramipril are effective anti hypertensive agents. But telmisartan has proved to have a better beneficial effect in prediabetics in preventing its progression to overt diabetes mellitus when compared to ramipril. However, large scale studies involving large number of patients should be conducted to establish the efficacy of the drugs. Telmisartan may be considered as one of the first line drugs in the treatment of stage 1 hypertension in pre diabetic patients.

\section{ACKNOWLEDGEMENTS}

Authors are grateful to Dr Sarib Rasool Khan, MD, Dr Mohan Rao, Principal and Dean, Dr A Santosh Kumari, Superintendent, and Dr Samiullah khan, Chief Administrative Officer, Ayaan Institute of Medical Sciences for permitting us to carry out the study.

Funding: No funding sources

Conflict of interest: None declared

Ethical approval: The study was approved by the Institutional Ethics Committee

\section{REFERENCES}

1. Chobanian AV, bakris GL, Black HR, Cushman WC, Green LA, Izzo JL Jr et al. The seventh report of the joint national committee or prevention, detection, evaluation \& treatment of high blood pressure: The JNC 7 report. JAMA. 2003;289:2560-72.
2. Ibrahim MM. Damasceno A. Hypertension in developing countries. Lancet. 2012;380:6.

3. Lawes CM, vender HS, Rodgers A. Global burden of blood pressure related disease, 2001 Lancet. 2008;371:513.

4. Epsterm M, Sowers JR. Diabetes mellitus \& hypertension. Hypertension 1992;19:403-18.

5. Sampanis C, Zamboules C. Arterial hypertension in diabetes mellitus: from theory to clinical practice. Hippokrata 2008;12:74-80.

6. ADA Guidelines prediabetes criteria. American diabetes association. Standards of medical care in diabetes - 2015. Diabetes Care. 2015;38(suppl. 1):S1S93.

7. Prediabetes. J Indian Medical Association. 2005.

8. Brunton LL. Goodman \& Gilmans: The pharmacological basis of therapeutics; 11th edition: section. Mc-Graw-Hill; 2006: 846.

9. Brunton LL. Goodman \& Gilmans: The pharmacological basis of therapeutics; 11th edition: section V/chapter 32/ Page 846.

10. Goodman \& Gilmans: The pharmacological basis of therapeutics; 11th edition: section V/chapter 32/ Page 846.

11. Ambade VN, Sharma YV, Somani BL. Methods of Estimation of Blood Glucose: A comparative evaluation. Med J Armed Forces India. 1998;54(2):131-2.

12. Gupta S, Jain U, Chauhan N. Laboratory Diagnosis of HbA1C: A Review. J Nanomed Res. 2017;5(4).

13. Isomaa $\mathrm{B}$, Almgren $\mathrm{P}$, Tuomi T. Cardiovascular morbidity \& mortality associated with the metabolic syndrome. American Diabetes Association. Diabetes Care. 2001;24(4): 683-9.

14. Unger $T$, Targeting cardiovascular protection: the concept of dual renin - angiotensin system control. Medscape J Med. 2008;10 (Suppl):S4.

15. Kaschina E, Grzesiak A, Li J, Foryst-Ludwig A, Timm M, Rompe F, et al. Angiotensin II type 2 receptor stimulation: a novel option of therapeutic interference with the renin-angiotensin system in myocardial infarction? Circulation. 2008;118(24): 2523-32.

16. Derosa G, Ragonesi PD, Mugellini A, Ciccarelli L, Fogari R. Effects of telmisartan compared with eprosartan on blood pressure control, glucose metabolism and lipid profile in hypertensive, type2 diabetic patients: a randomized, double-blind, placebo-controlled 12-month study. Hypertens Res. 2004;27(7):457-64.

17. Benson SC, Pershadsingh HA, Ho CI. Identification of telmisartan as a unique angiotensin II receptor antagonist with selective PPAR gamma modulating activity. Hypertension. 2004;43:993-1002.

18. Battershill AJ, Scott LJ. Telmisartan. A review of its use in the management of hypertension. Drugs. 2006;66(1):51-83.

19. Clasen R, Schupp M, Foryst-Ludwig A, Sprang C, Clemenz M, Krikov $M$, et al. PPAR gammaactivating angiotensin type-1 receptor blockers 
induce adiponectin. Hypertension. 2005;46(1):13743.

20. Berg AH, Scherer PE. Adipose tissue, inflammation, and cardiovascular disease. Circulation Res. 2005;96:939-49.

21. Han SH, Quon MJ, Kim JA, Koh KK. Adiponectin and cardiovascular disease: response to therapeutic interventions. J Am Coll Cardiol. 2007;49:531-8.

22. Scheen AJ. DREAM Study: Prevention of type 2 Diabetes with Ramipril and / or Rosiglitazone in persons with Dysglycaemia but no cardiovascular disease. Reviewed Med Liege. 2006;61(10):728-32.

Cite this article as: Ansari $\mathrm{A}$, Raoof $\mathrm{A}$. The comparative study of the effect of telmisartan and ramipril on diabetic profile in hypertensive prediabetic patients. Int $\mathrm{J}$ Basic Clin Pharmacol 2020;9:1269-74. 